\title{
Barriers to AV Bus Acceptance: A U.S. National Survey and Research Agenda
}

\author{
Connor Esterwood $^{\mathrm{a}}$, X. Jessie Yang $^{\mathrm{b}}$ and Lionel P. Robert Jr. ${ }^{\mathrm{a}}$

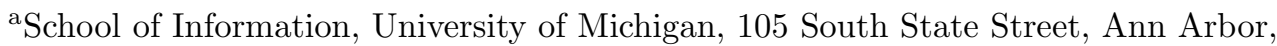 \\ Michigan, USA; ${ }^{\mathrm{b}}$ Industrial \& Operations Engineering, University of Michigan, 1205 Beal \\ Ave, Ann Arbor, Michigan, USA
}

\begin{abstract}
Automated Vehicle (AV) buses hold great potential, yet it is not clear if Americans will choose to ride them. Trust and attitudes, often influenced by individual differences, are vital predictors of technology acceptance and AVs are no exception. To deepen our understanding of individual differences as they pertain to AV buses, this paper presents the results of a national survey of 401 participants located in the United States of America. Findings from this survey indicate that individual differences influenced trust, attitude, and intention to ride AV buses. Specifically, trust in AV buses differed by individual's age and bus riding frequency while attitude toward AV buses differed by individual's age, ethnicity, and bus riding frequency. Finally, intention to ride an $\mathrm{AV}$ bus differed by age, gender, ethnicity, and bus riding frequency. Based on these results, we, propose a research agenda that seeks to inform future research on acceptance of AV buses.
\end{abstract}

\section{KEYWORDS}

Autonomous vehicles; Driverless bus; Shared autonomous vehicle; Autonomous buses; Public transportation; Technology acceptance; Individual differences;

Autonomous buses acceptance; Autonomous buses trust

\section{INTRODUCTION}

Automated Vehicle (AV) buses are small to mid-sized vehicles capable of transporting up to 10-15 passengers between two or more points on a designated route without input from an operator or passenger. Existing literature has defined AV buses as "a vehicle with rubber tires which-given its dimensions and its steering system - can be used in ordinary road traffic without geographical restriction, even if only in reduced power mode or at reduced speed" (Sinner, Weidmann, \& Nash, 2017). These vehicles are growing in popularity and examples of this technology in use can be seen anywhere from university campuses to office parks and even in public spaces in European cities (Iclodean, Cordos, \& Varga, 2020).

AV buses can be leveraged to benefit society, yet it is not clear if Americans will choose to accept (i.e. ride) them. AV buses have the potential to improve existing public bus services by decreasing transit operation costs, improving bus access, (Abraham et al., 2017; Gkartzonikas \& Gkritza, 2019; Iclodean et al., 2020) and increasing

CONTACT: Lionel P. Robert Jr. EMAIL: lprobert@umich.edu 
overall transportation efficiency (Du, Robert Jr., Tilbury, Pradhan, \& Yang, 2018; Faisal, Yigitcanlar, Kamruzzaman, \& Currie, 2019; Gkartzonikas \& Gkritza, 2019; Martinez \& Crist, 2015; Paddeu, Parkhurst, \& Shergold, 2020). Despite these positive attributes, many Americans are still skeptical of AV technologies in general (Ghazizadeh, Peng, Lee, \& Boyle, 2012; Gkartzonikas \& Gkritza, 2019; Haspiel et al., 2018; Petersen, Robert, Yang, \& Tilbury, 2019; Petersen, Zhao, Tilbury, Yang, \& Robert, 2018; Q. Zhang, Robert Jr.; Lionel P., Du, \& Yang, 2018) and AV buses specifically (Nordhoff et al., 2017).

Trust and attitude are vital drivers of whether someone will accept a given technology (J. D. Lee \& See, 2004) and AVs are no exception (Bansal \& Kockelman, 2018; Bazilinskyy, Kyriakidis, \& de Winter, 2015; Biondi, Alvarez, \& Jeong, 2019; Choi \& Ji, 2015; Gkartzonikas \& Gkritza, 2019; Hegner, Beldad, \& Brunswick, 2019; Verberne, Ham, \& Midden, 2012; T. Zhang et al., 2019). Generally, when individuals trust a technology and have a positive attitude towards it, they are much more willing to employ it (Esteva Armida, 2008; "Modeling Consumers' Adoption Intentions of Remote Mobile Payments in the United Kingdom: Extending UTAUT with Innovativeness, Risk, and Trust", 2015; Oliveira, Faria, Thomas, \& Popovič, 2014). Research on AVs and AV buses has confirmed that both attitude and trust are vital to their acceptance (Creech et al., 2017; Haspiel et al., 2018; Jayaraman et al., 2018; Nordhoff et al., 2018, 2017; Paddeu et al., 2020; Petersen, Tilbury, Robert, \& Yang, 2017).

Trust and attitudes regarding technologies have shown to differ significantly between individuals, yet we know very little about their impacts on AV buses (Azad, Hoseinzadeh, Brakewood, Cherry, \& Han, 2019; Robert et al., 2020). Individual differences in trust and attitude regarding technology can be profound (Robert et al., 2020). Existing literature supports the importance of individual differences on the acceptance of technology. For example, several studies have found that gender and age are important drivers of the acceptance of many types of technology (Hauk, Hüffmeier, \& Krumm, 2018; Venkatesh \& Morris, 2000). Similarly, individual differences such as age, gender, and education have also shown to be important to understanding trust and attitudes toward new technologies (Haboucha, Ishaq, \& Shiftan, 2017; Manawadu, Ishikawa, Kamezaki, \& Sugano, 2015; Souders \& Charness, 2016). Therefore, the lack of attention on individual differences and their impacts on factors such as AV bus trust, attitude, intention greatly hinders our understanding of the potential challenges to the acceptance of AV buses.

To address this shortcoming, we conducted a large national representative survey of frequent and in-frequent U.S. bus riders. This survey targeted a representative sample of 428 continental U.S. bus riders based on age, gender, ethnicity, and geographic region. We examined the potential differences in trust, attitudes and intentions to ride an AV bus based on their ethnicity, gender, age and geographic region. Results show that differences exist based on individual characteristics. Specifically, for trust, differences exist between certain age groups and frequency of bus riding. For attitude, differences exist between age groups, frequency of bus riding, and ethnic group. For intention, differences exist between age groups, gender, frequency of bus riding, and ethnic group. This paper contributes to our understanding of the acceptance of AV buses over and above the existing literature in the following ways. First, to the best of our knowledge, no national survey has been conducted in the United States regarding trust, attitudes, and acceptance of AV buses. This survey's breakdown of the U.S. population is wide-reaching and allows for a meaningful and informative statistical analysis. Second, we provide a research agenda that helps to guide our current conversations on the acceptance of AV buses. 


\section{BACKGROUND}

\subsection{Individual Differences and Technology Acceptance}

Individual differences are important for understanding technology acceptance and demographic variables have often been used to understand such differences. A wealth of literature has investigated these differences primarily looking at the differences due to age, gender, and ethnicity and/or racial group (Gefen \& Straub, 1997; Hauk et al., 2018; Holguín-Veras \& Wang, 2011; Hulse, Xie, \& Galea, 2018; D. Kim, Chun, \& Lee, 2014; Mitchell, Chebli, Ruggiero, \& Muramatsu, 2019; Moris \& Venkatesh, 2000; Schnall \& Bakken, 2011; Venkatesh \& Morris, 2000). Below, we present and discuss the individual differences that have been shown to influence technology acceptance.

Difference attributed to gender has been found throughout the technology acceptance literature. For example, Venkatesh and Morris (2000) found gender differences in the acceptance of workplace technology. They found that men and women were driven to adopt technology for fundamental different reasons. More specifically, men were motivated by instrumental factors while women were driven more by procedural and social factors. The literature on $\mathrm{AVs}$ has also identified similar patterns in acceptance between males and females. For example, Hulse et al. (2018) found that men and women had significantly different degrees of acceptance where men were more likely to accept AVs than women. Consistent with Hulse et al. (2018), Charness, Yoon, Souders, Stothart, and Yehnert (2018) also found significant differences between men and women in terms of AVs. Once again males were more likely to accept AVs than women.

Age is another commonly studied difference in relation to technology acceptance. For instance, Moris and Venkatesh (2000) found that age significantly impacted technology acceptance. Specifically, older users adopted technologies for different reasons than younger users. In particular, older users were more influenced by subjective norm and perceived behavioral control while younger users were more influenced by attitudes toward a technology. A recent meta-analysis study by Hauk et al. (2018) further highlighted the importance of age on technology acceptance. In their meta-analysis, age was found to be negatively related to the acceptance of many types of technologies. Generally, their meta-analysis confirmed what many already assumed, older users are less likely to accept new technology than their younger counterparts. Interestingly, Hauk et al. (2018) also found that these effects diminished for technologies addressing specific needs of older adults. Consistent with these studies, the AV literature has also found that younger populations are more likely to accept AVs than older populations (Charness et al., 2018; Hulse et al., 2018; Rödel, Stadler, Meschtscherjakov, \& Tscheligi, 2014).

Though existing literature on technology acceptance focuses primarily on age and gender, more recent studies are showing that ethnic group and/or racial identity might play a role. One such study was Holguín-Veras and Wang (2011) which found that adoption of automatic toll-way passes was significantly different by ethnicity. Specifically, individuals who identified as White were more likely to use automatic toll-way passes than individuals who identified as an ethnic minority. A separate study by, Schnall and Bakken (2011) also found that ethnicity significantly impacted intention to use an electronic medical record system. Specifically, those identifying as non-Hispanics had higher intention to use the system than those identifying as Hispanic. Similarly, Mitchell et al. (2019) found that individuals who identified as Black and Hispanic were less likely to use technology for health-related purposes than individuals who identified 
as White. Finally, D. Kim et al. (2014) identified ethnicity as a distinctive determinant between current adopters and non-adopters of smartphones for USA college students. This study found that individuals identifying as White were less likely to adopt smartphones than those that identified as non-white. Taking these studies into account, it appears that ethnicity can be important to understanding acceptance of technology including AVs.

Similarly, individual differences in technology acceptance based on geographic region has also been overlooked. Despite calls to include the impacts of geographic and cultural contexts (Azad et al., 2019; Baptista \& Oliveira, 2015). Yet, there is still much to learn with regards to the impact of geographic and cultural context on technology acceptance. In the case of AV buses, prior research has shown that the popularity of public transportation can vary greatly by geographic region in the U.S. (HughesCromwick, 2019; Neff \& Dickens, 2013). Therefore, this study examines the potential impacts of geographic region.

In sum, it is clear, individual differences are important to understanding technology acceptance. This study seeks to understand the impact these differences have on the acceptance of autonomous buses. In doing so, we hope to contribute to the literature by identifying when or if such differences matter with regards to the acceptance of AV buses and which differences are most influential.

\subsection{Trust, Attitude and Intention}

Research on technology acceptance has identified trust, attitude and intention as important predictors of technology acceptance. First, trust has been repeatedly linked to the technology acceptance (Biondi et al., 2019; Choi \& Ji, 2015; Du et al., 2019; Hegner et al., 2019; J. D. Lee \& See, 2004; Liu, Yang, Wang, \& Liu, 2019; Paddeu et al., 2020; Venkatesh, Morris, Davis, \& Davis, 2003). Trust has been conceptualized as one's belief in the functionality, helpfulness, and reliability of a given technology (Mcknight, Carter, Thatcher, \& Clay, 2011; You \& Robert, 2019). Numerous studies have demonstrated that individuals will hesitate to employ a technology they do not trust (Du et al., 2018; Fraedrich, Cyganski, Wolf, \& Lenz, 2016; Ghazizadeh et al., 2012; Haspiel et al., 2018; Kaur \& Rampersad, 2018; Petersen et al., 2019, 2018; Q. Zhang et al., 2018). That being said, understanding whether or not trust in a technology differs individually would be vital to understanding acceptance AV buses.

Second, attitude is an important variable for explaining technology acceptance (Bobbitt \& Dabholkar, 2001; Hegner et al., 2019; Y. J. Kim, Chun, \& Song, 2009; Robert Jr \& Sykes, 2017; Taylor \& Todd, 1995; Yang \& Yoo, 2004). Attitude can be defined as an individual's favorable or unfavorable feelings about a particular object (Bagozzi \& Burnkrant, 1985; Kothandapani, 1971; Ostrom, 1969). Generally, the more positive an attitude someone has toward a technology, the more likely they are to accept that technology (Davis \& Venkatesh, 1996). Indeed, several prominent models of technology acceptance include attitude as a key construct (Ajzen, 1991; Dwivedi, Rana, Jeyaraj, Clement, \& Williams, 2019; Hewitt, Politis, Amanatidis, \& Sarkar, 2019; Mathieson, 1991; Taylor \& Todd, 1995; Venkatesh et al., 2003). Given attitude's important role in prior literature this paper investigates this construct in terms of attitude toward riding in $\mathrm{AV}$ buses.

Finally, intention is a variable of great interest given its strong link to acceptance (Ajzen, 1991; Sheppard, Hartwick, \& Warshaw, 1988; Taylor \& Todd, 1995). Intention can be defined as "a person's subjective probability that he/she will preform some be- 
havior" (Fishbein \& Ajzen, 1975, p.288). Over the years, several theories have placed intention as a vital construct in understanding human behavior in general and technology use specifically (Dwivedi et al., 2019; Fishbein \& Ajzen, 1975; Mathieson, 1991; Venkatesh et al., 2003). Due to trust, attitude, and intention's relative importance to theories related to technology acceptance, this paper includes them as key outcomes in this study.

Several studies have examined trust, attitude, and intention to use in the context of AV acceptance. For example, Choi and Ji (2015) found that trust was positively associated with behavioral intention and AV acceptance. Similarly, Liu et al. (2019) also demonstrated that trust was positively associated with acceptance of both fully and semi-autonomous vehicles. Research, by Yuen, Chua, Wang, Ma, and Li (2020) has identified attitudes as an important factor in determining the acceptance of AVs. Finally Hewitt et al. (2019) argues for a link between behavioral intention and use behavior in their proposed Autonomous Vehicle Acceptance Model. In all, there is an emerging consensus that trust, attitudes and beliefs about intention to use are also important to understanding the acceptance of AVs.

\section{METHOD}

\subsection{Survey Data Collection}

This study utilized surveys distributed online via the Qualtrics platform. Surveys were structured so as to gather demographic information, followed by randomly ordered blocks of modified questionnaires investigating intention, attitude and trust. The intention and attitude items were modified from the work of Davis and Venkatesh (1996), and trust from Muir and Moray (1996). The total number of items for each construct were kept to a minimum so as to encourage questionnaire completion and reduce participant fatigue.

Trust was measured via four items. One such item was "What degree of faith do you have that an autonomous bus will be able to cope with all systems states in the future?". Responses ranged between 1 indicating "not at all" and 10 indicating "completely". A complete list of items used is visible in Table A1. Attitude was measured via 5 items. One such item was "Overall, I find riding an autonomous bus to be a wise move". Responses to these items ranged from 1 indicating "strongly disagree" to 7 indicating "strongly agree". A complete list of items used is visible in Table A2. Finally, intention was measured via 4 items. An example of an item utilized was "If possible I expect to ride an autonomous bus in the future". Responses to this item ranged from 1 indicating "strongly disagree" to 7 indicating "strongly agree". A complete list of items used is visible in Table A3.

To ensure data quality we included validation questions. Validation questions were questions included only to ensure that the participants were paying attention while completing the survey. An example of a validation question was: "this is a validation question. Please select neither agree nor disagree". If a participant failed to answer a validation question correctly, the survey session would terminate and the participant's data would be excluded from the analysis. The survey included questions that measured how frequency someone currently used buses.

Data collection took place between March and April of 2019. Generally speaking news coverage of autonomous vehicles of all kinds was fairly positive, however, the effects of an automotive accident involving an Uber self-driving vehicle (Higgins, 2017) 
was still present though its influence may be diminished by this time (C. Lee et al., 2018).

\subsection{Sample}

The population was recruited to represent the average bus riding population in the continental U.S. based on a comprehensive survey of 695,748 passengers completed from 2008 to 2015 (see Clark, American Public Transportation Association, and CJI Research Corporation (2017)). Table 1 below presents our sample compared to that of the population identified by Clark et al. (2017). These participants were recruited via a Qualtrics ${ }^{\complement}$ market research panel where participants opt-in for notification and participation in online research studies. The total number of participants for this study was 428. Participants were distributed among four different regions. $36 \%$ of participants were from the South, 23\% from the Midwest, $22 \%$ from the West, and $19 \%$ from the Northeast. The participants demographic breakdown on gender identification include: $48 \%$ identified as male and $52 \%$ identified as female. The breakdown by age include: $38 \%$ were between 18 and 44, $40 \%$ between 45 and 64 and $22.7 \%$ were 65 and up. Bus use frequency was distributed where 182 participants were frequent bus riders and 219 were in-frequent bus riders.

\begin{tabular}{l|ll} 
Age & Clark (2017) & Present Study \\
\hline Under 18 & $10 \%$ & $\mathrm{n} / \mathrm{a}$ \\
$\mathbf{1 8}-\mathbf{4 4}$ & $43 \%$ & $38 \%$ \\
$\mathbf{4 5}-\mathbf{6 4}$ & $36 \%$ & $40 \%$ \\
$\mathbf{6 5}$ \& Up & $7 \%$ & $22.7 \%$ \\
\hline Ethnicity & & \\
White or Caucasian & $63 \%$ & $63 \%$ \\
Black or African American & $12 \%$ & $12 \%$ \\
Hispanic & $17 \%$ & $14 \%$ \\
Asian or Asian American & $5 \%$ & $4 \%$ \\
Other & $3 \%$ & $7 \%$ \\
Gender & & \\
Male & $45 \%$ & $48 \%$ \\
Female & $55 \%$ & $52 \%$ \\
\hline
\end{tabular}

Table 1. Present Study's Sample vs. Population Results of Clark et al. (2017)

\subsection{Survey Results}

Results were compiled and analyzed in $\mathrm{R}$ via the $\mathrm{R}$ Studio software suite. Our analysis consisted of an analysis of variance (ANOVA) followed by a post-hoc Tukey HSD for a pairwise comparison of means. This study's analysis involved multiple pairwise comparisons which increases the chance of a type 1 error (false positive). To avoid this problem, a Tukey HSD was used for detecting significant effects. The Tukey HSD provides a more robust test of significance than pairwise comparison without correc- 
tion (Allen, 2017). The outcome measures were trust, attitude, and intention and the demographic traits assessed were age, ethnicity, gender, continental U.S. region, and frequency of bus riding.

\subsection{Trust}

A summary of findings in relation to trust are shown in table 2 .

\begin{tabular}{|c|c|c|c|c|c|}
\hline Characteristic & $\mathbf{N}$ & Means & SE & $\mathbf{F}$ & P-Val \\
\hline Age & & & & 3.56 & 0.03 \\
\hline $18-44$ & 162 & 6.44 & 0.16 & & \\
\hline 45-64 & 169 & 5.94 & 0.18 & & \\
\hline $65 \&$ Up & 97 & 5.74 & 0.24 & & \\
\hline Ethnicity & & & & 1.40 & 0.23 \\
\hline Asian & 20.00 & 7.13 & 0.38 & & \\
\hline Black or African American & 51.00 & 5.98 & 0.32 & & \\
\hline Hispanic or Latin American & 59.00 & 6.29 & 0.23 & & \\
\hline Other & 29.00 & 5.87 & 0.40 & & \\
\hline White & 269.00 & 6.01 & 0.14 & & \\
\hline Gender & & & & 3.74 & 0.05 \\
\hline Male & 204.00 & 6.31 & 0.15 & & \\
\hline Female & 223.00 & 5.89 & 0.15 & & \\
\hline Frequency of Use & & & & 21.9 & $<0.01$ \\
\hline Frequent & 182 & 6.59 & 0.15 & & \\
\hline In-Frequent & 219 & 5.60 & 0.15 & & \\
\hline Region & & & & 0.59 & 0.62 \\
\hline Midwest & 98 & 5.85 & 0.23 & & \\
\hline Northeast & 80 & 6.15 & 0.27 & & \\
\hline South & 150 & 6.23 & 0.17 & & \\
\hline West & 90 & 6.07 & 0.24 & & \\
\hline
\end{tabular}

Table 2. Trust by Individual Differences

Age group was significant $(\mathrm{F}(2,425)=3.56, \mathrm{p}<.05)$. A post-hoc investigation revealed a significant difference between trust scores for the 18-44 and $65+$ group $(\mathrm{p}=$ $0.0 .04)$ but not between the 18-44 and 45-64 group ( $\mathrm{p}=0.10)$ or between $45-64$ and $65+$ group $(\mathrm{p}=0.76)$. These findings indicate that in terms of trust, differences exist only between the 18-44 and 65+ age groups. Specifically, the 18-44 age group had higher trust in AV buses than the 65 and up age group (Figure 1). 
Figure 1. Trust by Age Groups

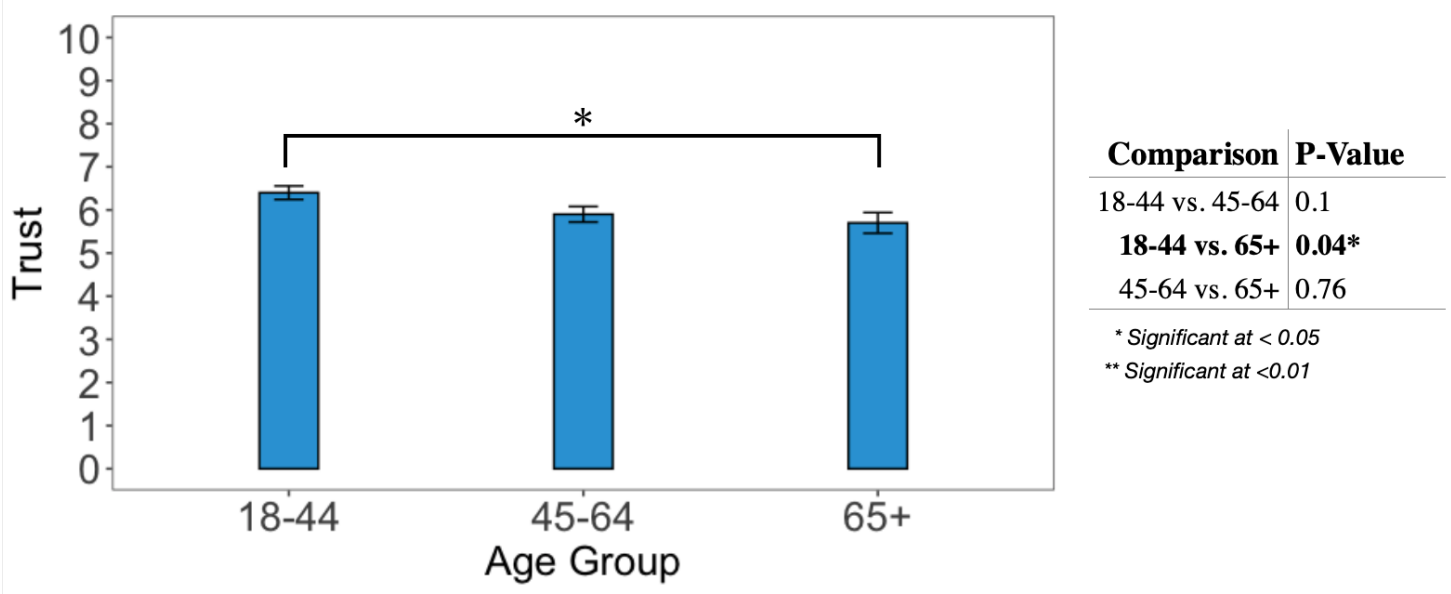

The effect of bus riding frequency was significant $(\mathrm{F}(1,426)=21.85, \mathrm{p}<0.01)$. Frequent bus riders had higher trust than those that are in-frequent bus riders (Figure 2).

Figure 2. Trust by Frequency of Bus Use

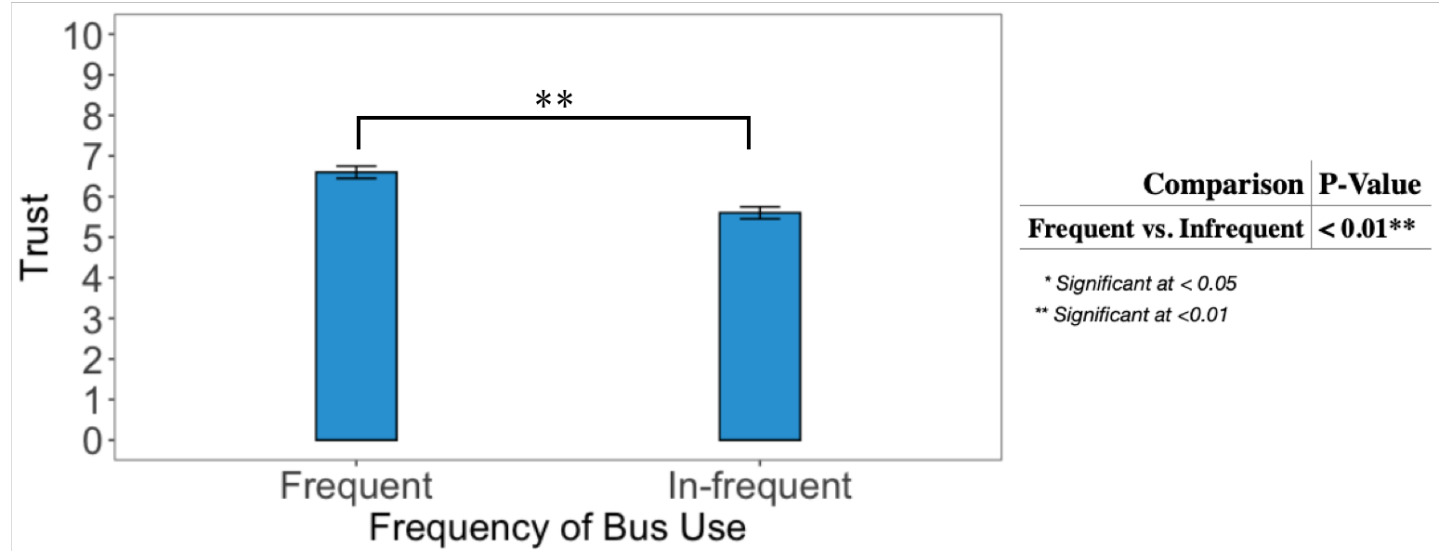

- Finding 1a: The 18 to 44 age group trusted AV buses more than the 65 and up age group.

- Finding 1b: Frequent bus riders trusted AV buses more than in-frequent riders.

\subsection{Attitude}

Attitude toward AV buses differed significantly across age groups $(\mathrm{F}(2,425)=15.19$, $\mathrm{p}<.01)$. In addition, differences were also found between frequent and in-frequent bus riders $(\mathrm{F}(1,426)=78.54, \mathrm{p}<.01)$, and individuals that identified as "Asian Americans" and individuals that identified as "White Americans" $(\mathrm{F}(4,423)=6.59$, $\mathrm{p}<.01)$. A summary of findings in relation to attitude is visible in 3 


\begin{tabular}{|c|c|c|c|c|c|}
\hline Characteristic & $\mathbf{N}$ & Means & SE & $\mathbf{F}$ & P-Val \\
\hline Age & & & & 15.19 & $<0.01$ \\
\hline $18-44$ & 162.00 & 4.54 & 0.13 & & \\
\hline $45-64$ & 169.00 & 3.97 & 0.12 & & \\
\hline $65 \& U p$ & 97.00 & 3.44 & 0.16 & & \\
\hline Ethnicity & & & & 4.376 & $<0.01$ \\
\hline Asian & 20.00 & 5.15 & 0.23 & & \\
\hline Black or African American & 51.00 & 4.21 & 0.21 & & \\
\hline Hispanic or Latin American & 59.00 & 4.29 & 0.20 & & \\
\hline Other & 29.00 & 4.56 & 0.36 & & \\
\hline White & 269.00 & 3.86 & 0.10 & & \\
\hline Gender & & & & 3.113 & 0.09 \\
\hline Male & 204.00 & 4.22 & 0.11 & & \\
\hline Female & 223.00 & 3.94 & 0.11 & & \\
\hline Frequency of Use & & & & 37.37 & $<0.01$ \\
\hline Frequent & 209.00 & 4.55 & 0.15 & & \\
\hline In-Frequent & 219.00 & 3.61 & 0.15 & & \\
\hline Region & & & & 2.02 & 0.11 \\
\hline Midwest & 98 & 3.99 & 0.18 & & \\
\hline Northeast & 80 & 3.78 & 0.19 & & \\
\hline South & 150 & 4.30 & 0.13 & & \\
\hline West & 90 & 3.98 & 0.17 & & \\
\hline
\end{tabular}

Table 3. Attitude by Individual Differences

Here again, age group was significant $(\mathrm{F}(2,425)=15.19, \mathrm{p}<.01)$. A post-hoc investigation revealed a significant difference between attitude scores for all age groups (45-64 vs. $18-44: \mathrm{p}<0.01-65+$ vs. $18-44: \mathrm{p}<0.01-65+$ vs. $45-64: \mathrm{p}=0.02)$. The 18 to 44 age group had the most positive attitude towards AV buses followed by the 45 to 64 age group and finally the $65+$ age group had the lowest attitude towards AV buses. This is displayed in Figure 3.

Figure 3. Attitude by Age Group

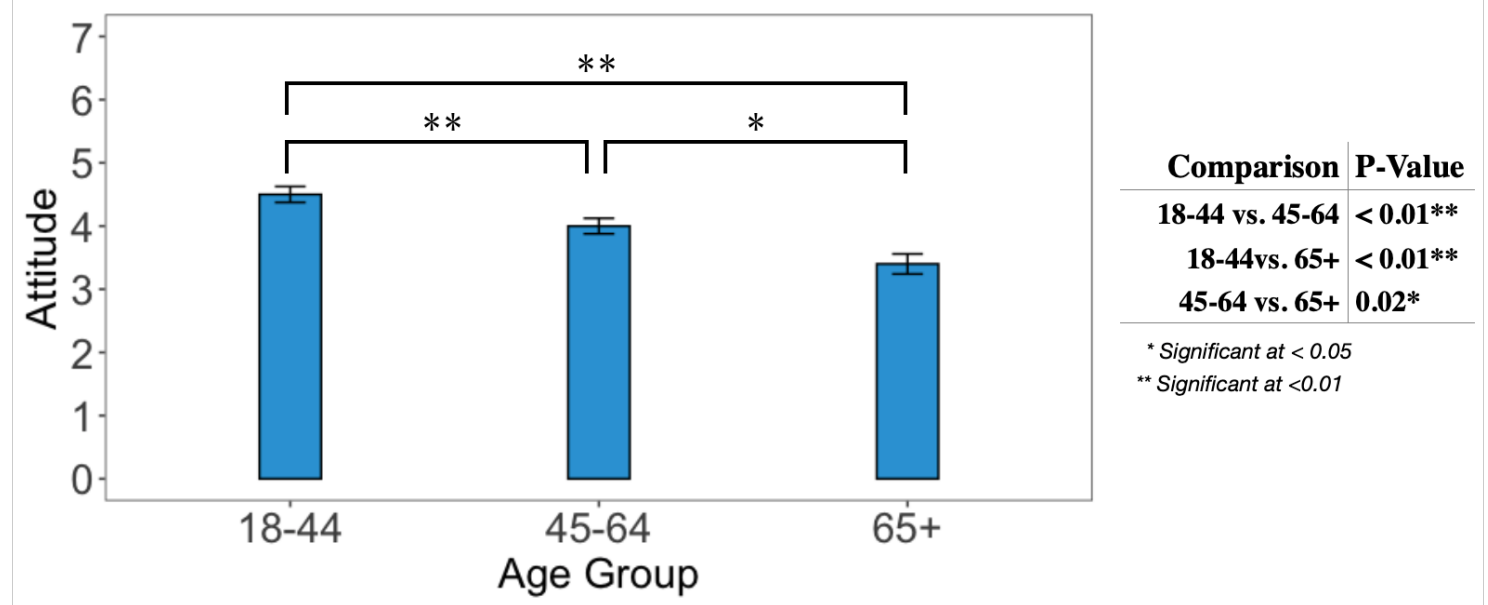

Attitude for different frequencies of bus riding was significant $(\mathrm{F}(1,426)=37.37$, $\mathrm{p}<.01)$. As with Trust, we see higher mean values on behalf of frequent riders when compared to those of in-frequent riders. This is visible in Figure 4. 
Figure 4. Attitude by Frequency of Bus Use

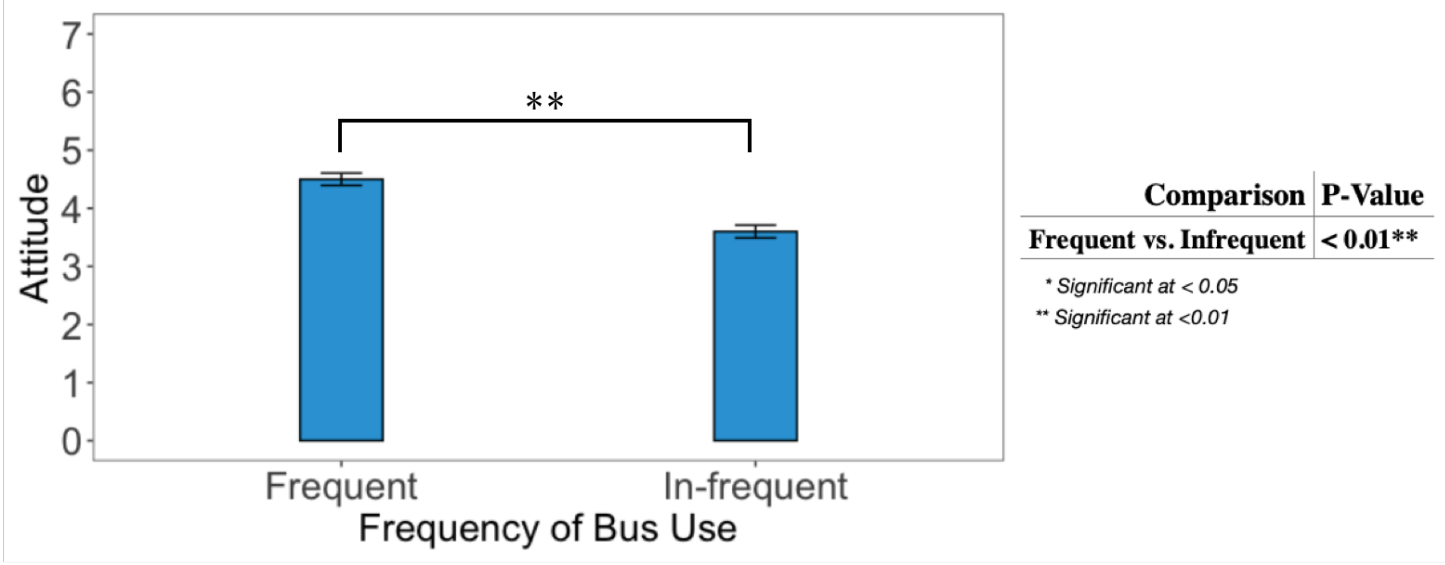

Attitude toward AV buses differed significant by ethnicity $(\mathrm{F}(4,423)=4.38, \mathrm{p}<.01)$. However, a post hoc-investigation only found significant differences between individuals identified as White Americans with those identified as Asian Americans $(\mathrm{p}<0.01)$. Asian American's attitudes toward AV buses was significantly higher than those that identified as White Americans. Figure 5 displays the attitude means by ethnic group below.

Figure 5. Attitude by Ethnic Group

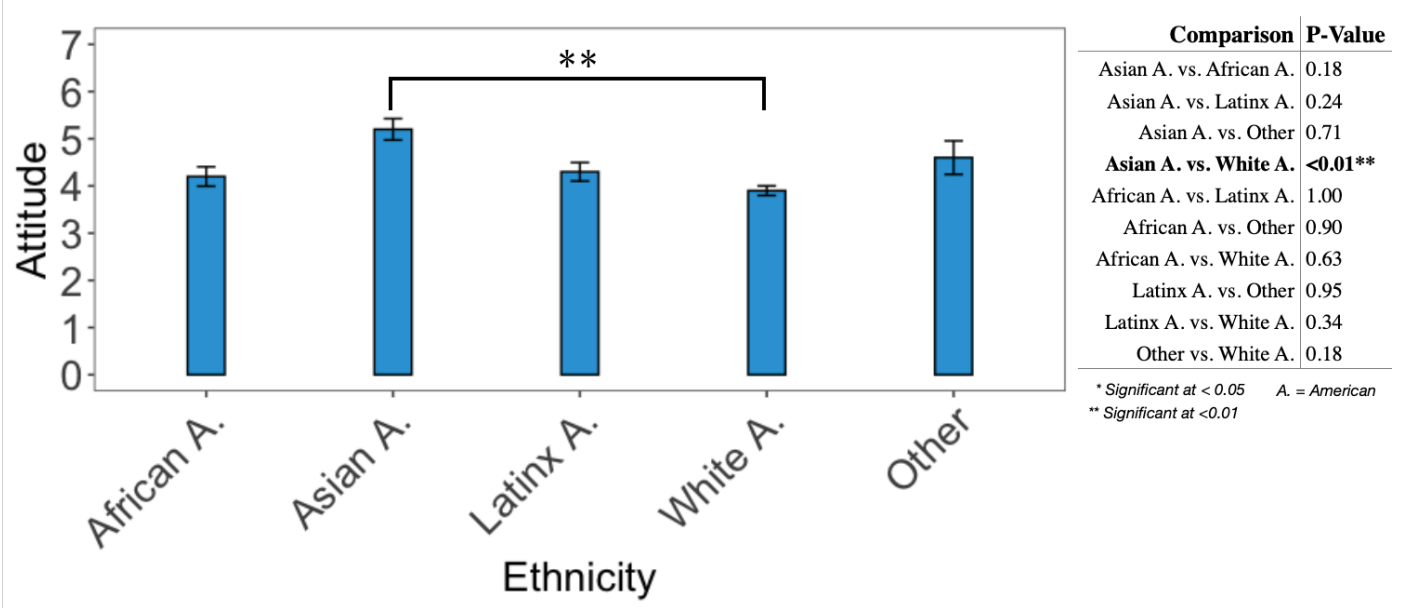

- Finding 2a: The 18 to 44 old age group had the most positive attitude towards AV buses followed by the 45 to 64 year old age group and the $65+$ age group respectively.

- Finding 2b: Frequent bus riders had a more positive attitude towards AV buses than in-frequent riders.

- Finding 2c: Asian Americans had a significantly more positive attitude towards AV buses than White Americans. 


\subsection{Intention}

Intention to ride $\mathrm{AV}$ buses differed significantly by: age $(\mathrm{F}(2,425)=30.90, \mathrm{p}<0.01)$, gender $(\mathrm{F}(1,425)=5.10, \mathrm{p}=0.03)$, frequency of bus riding $(\mathrm{F}(1,426)=78.54, \mathrm{p}$ $<0.01)$, and ethnicity $(\mathrm{F}(4,423)=6.59, \mathrm{p}<.01)$. A summary of findings in relation to attitude is visible in table 4 .

\begin{tabular}{|c|c|c|c|c|c|}
\hline Characteristic & $\mathbf{N}$ & Means & SE & $\mathbf{F}$ & P-Val \\
\hline Age & & & & 30.9 & $<0.01$ \\
\hline $18-44$ & 162 & 4.91 & 0.14 & & \\
\hline 45-64 & 169 & 4.24 & 0.14 & & \\
\hline $65 \& U p$ & 97 & 3.09 & 0.18 & & \\
\hline Ethnicity & & & & 6.589 & $<0.01$ \\
\hline Asian & 20 & 5.63 & 0.23 & & \\
\hline Black or African American & 51 & 4.55 & 0.26 & & \\
\hline Hispanic or Latin American & 59 & 4.67 & 0.22 & & \\
\hline Other & 29 & 4.83 & 0.36 & & \\
\hline White & 269 & 3.91 & 0.12 & & \\
\hline Gender & & & & 5.097 & 0.03 \\
\hline Male & 204 & 4.46 & 0.14 & & \\
\hline Female & 223 & 4.04 & 0.13 & & \\
\hline Frequency of Use & & & & 78.54 & $<0.01$ \\
\hline Frequent & 209 & 5.01 & 0.12 & & \\
\hline In-Frequent & 219 & 3.49 & 0.12 & & \\
\hline Region & & & & 0.93 & 0.43 \\
\hline Midwest & 98 & 4.06 & 0.21 & & \\
\hline Northeast & 80 & 4.06 & 0.22 & & \\
\hline South & 150 & 4.37 & 0.15 & & \\
\hline West & 90 & 4.40 & 0.20 & & \\
\hline
\end{tabular}

Table 4. Intention by Individual Differences

Intention to ride an AV bus differed significantly by age groups $(\mathrm{F}(2,425)=30.90$, $\mathrm{p}<0.01$ ). A post hoc-investigation revealed significant differences between intention to ride for all age groups (45-64 vs. $18-44: \mathrm{p}<0.01-65+$ vs. $18-44: \mathrm{p}<0.01-65+$ vs. 45-64: $\mathrm{p}<0.01$ ). Again, we see that intention to ride was highest for the 18-44 age group followed by the $45-64$ age group and finally the 65 and up age group. This is visible in Figure 6. 
Figure 6. Intention to Ride by Age Group

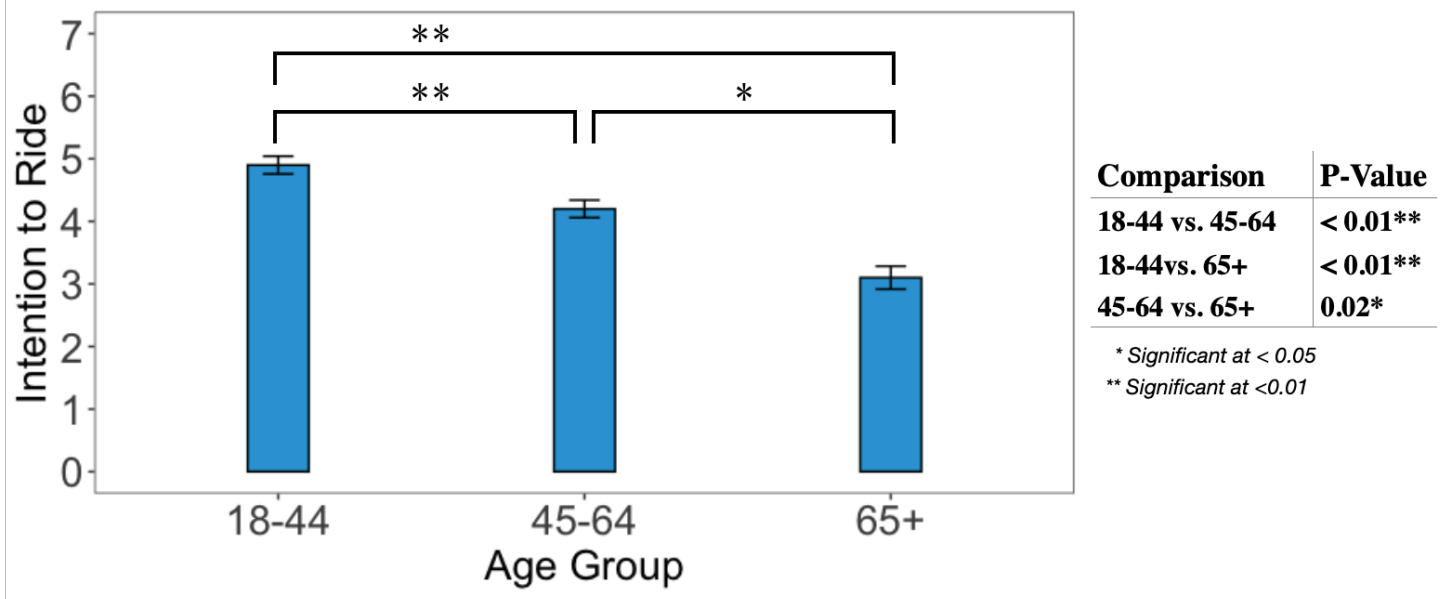

Intention to ride an $\mathrm{AV}$ bus differed significantly by gender $(\mathrm{F}(1,425)=5.10, \mathrm{p}=$ 0.03). Males had slightly higher intention to ride an AV bus than females as shown in Figure 7.

Figure 7. Intention to Ride by Gender

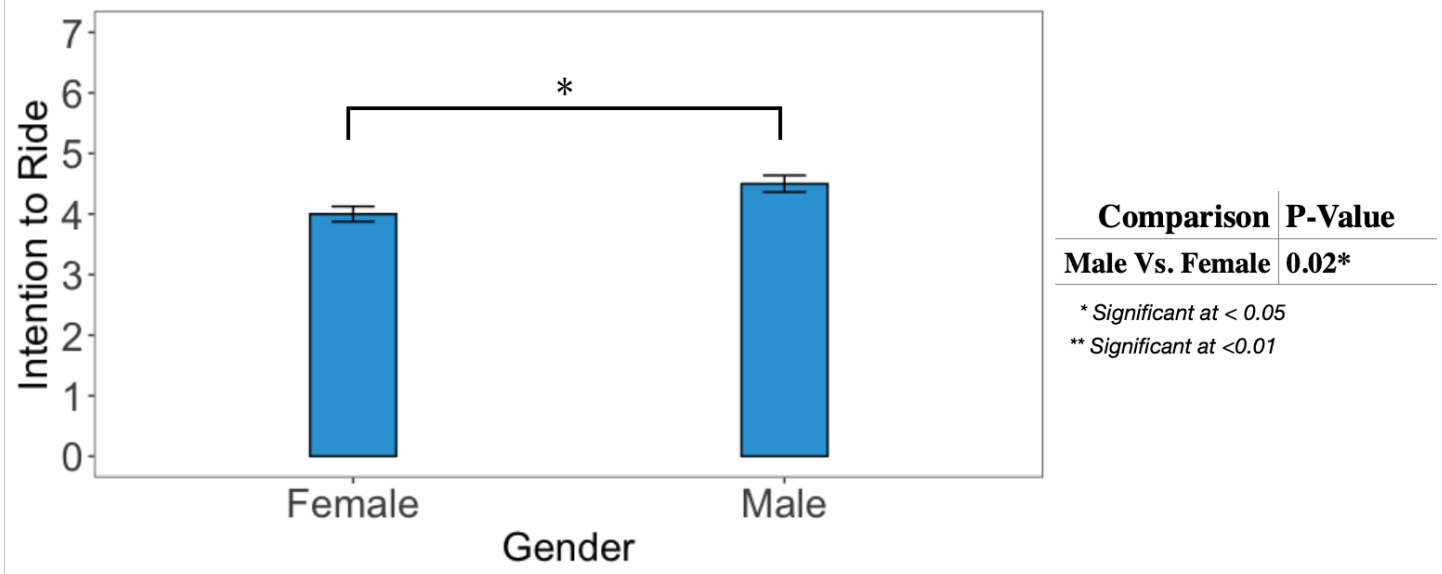

Intention to ride an $\mathrm{AV}$ bus differed significantly between frequent and infrequent bus riders $(\mathrm{F}(1,426)=78.54, \mathrm{p}<.01)$. Frequent riders were found to have higher intention to ride an AV bus than infrequent riders. This is seen in Figure 8. 
Figure 8. Intention to Ride by Frequency of Bus Use

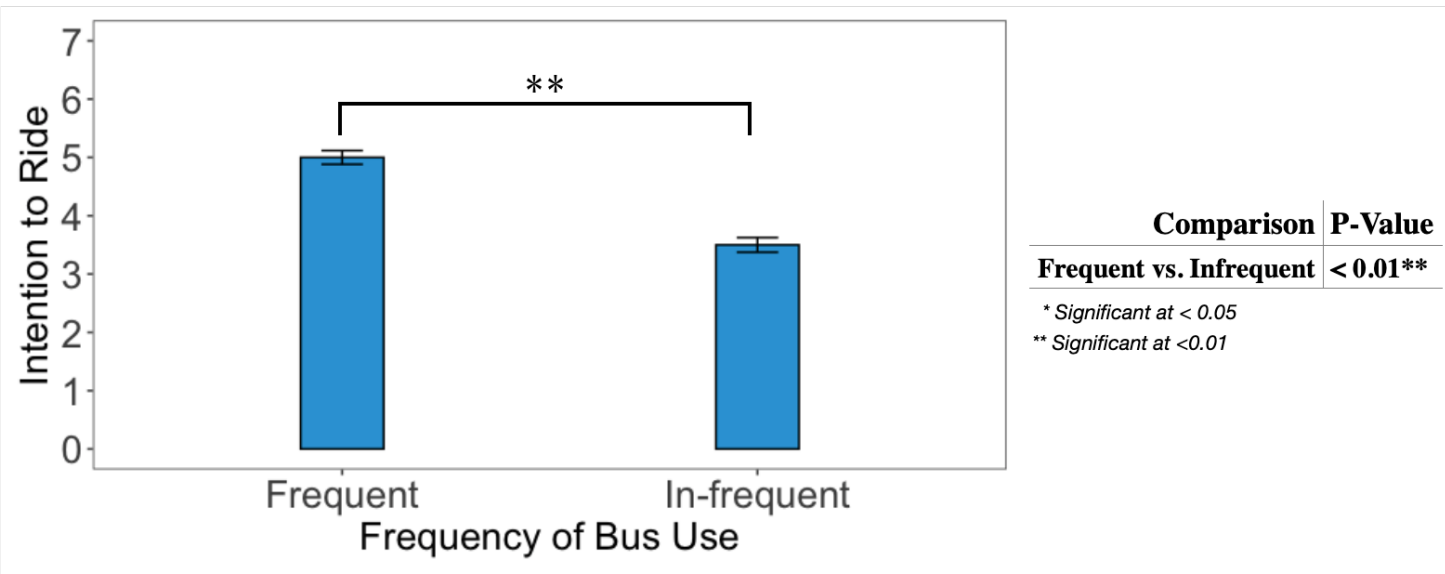

Finally, intention to ride an AV bus also differed significantly across ethnicity ( $\mathrm{F}(4$, $423)=6.59, \mathrm{p}<0.01)$. A post hoc-investigation revealed significant differences between those that identified as White Americans and those that identified as Asian Americans $(\mathrm{p}<0.01)$, as well as a significant difference between those that identified as White Americans and those that identified as Latinx Americans $(p=0.04)$. The mean for Asian Americans was higher than White Americans and the mean for Latinx Americans was also higher than White Americans. However, there were no significant differences between Asian Americans and Latinx Americans. Intention to ride means by ethnic group are visible in Figure 9 .

Figure 9. Intention to Ride by Ethnic Group

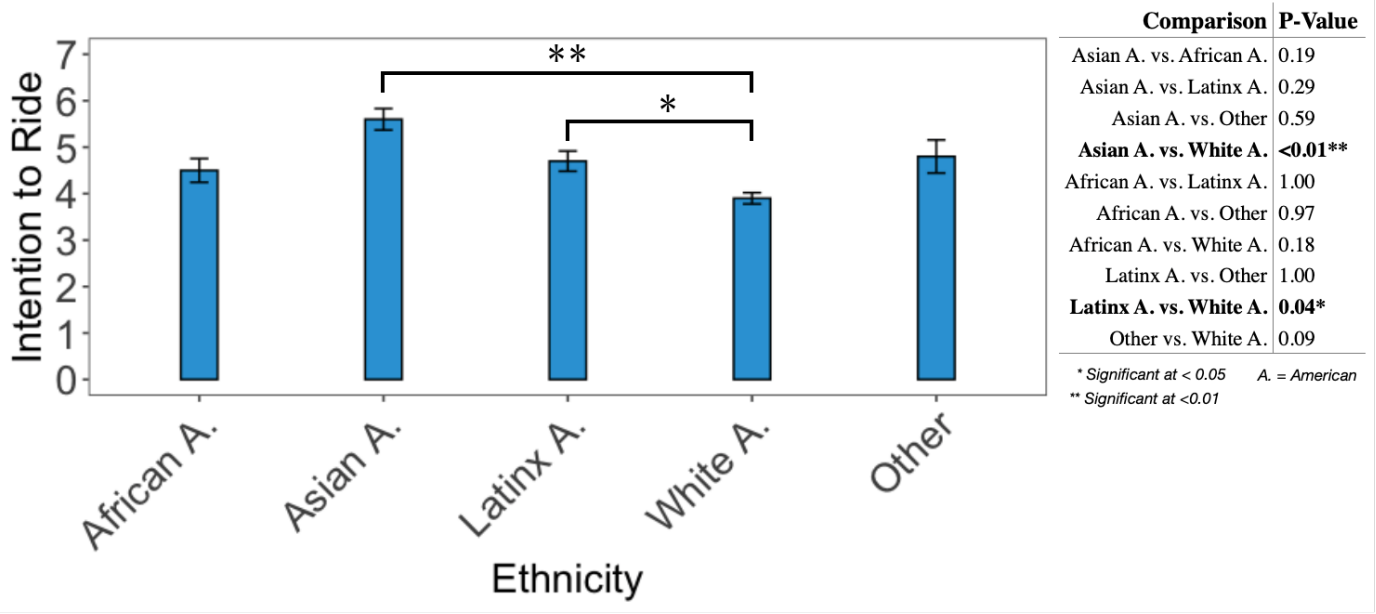

- Finding 3a: The 18 to 44 age group had the highest intention to ride followed by the 45 to 65 age group followed by the 65 and up age group.

- Finding 3b: Males had higher ratings for intention to ride than females.

- Finding 3c: Frequent bus riders had higher intention to ride than in-frequent bus riders.

- Finding 3d: : Individuals identifying as Asian Americans and Individuals iden- 
tifying as Latinx Americans had higher intention to ride than those identifying as White Americans.

\subsection{Summary of Results}

The results of this study provide insight into how individual differences relate to the general U.S. population's trust in, attitude toward, and intention to ride an AV bus. Based on the results of this study it appears that frequency of use, and age group are somewhat universally important across all 3 of our outcomes. In addition to this observation we also see an interesting pattern where we observed a larger number of significant factors for some of our outcomes than for others. Namely, intention to ride an AV bus was significantly influence by 4 different factors (age group, gender, frequency of use, and ethnicity) while attitude was influenced by 3 (age group, frequency of use, and ethnicity) and trust only by 2 (age group and frequency of use). These results as well as the individual findings presented above and in table 5 raise many questions. The remainder of this paper seeks to organize these questions in a research agenda with the goal of jump-starting future research related to trust in, attitude towards, and interning to ride AV buses.

\begin{tabular}{|c|c|c|}
\hline Outcome & Demographic Trait & Summary \\
\hline \multirow[t]{2}{*}{ Trust } & Age & 18-44 year olds have higher trust than those $65+$ \\
\hline & Frequency of Use & $\begin{array}{l}\text { Frequent public transit riders have higher trust than } \\
\text { in-frequent public transit riders. }\end{array}$ \\
\hline \multirow[t]{3}{*}{ Attitude } & Age & $\begin{array}{l}18 \text { to } 44 \text { year olds had the highest ratings for attitude } \\
\text { followed by } 45 \text { and } 64 \text { year olds and individuals who } \\
\text { were } 65+\text { sequentially. }\end{array}$ \\
\hline & Frequency of Use & $\begin{array}{l}\text { Frequent riders of conventional public transportation } \\
\text { had higher ratings for attitude than in-frequent riders. }\end{array}$ \\
\hline & Ethnicity & $\begin{array}{l}\text { Individuals identifying as Asians had significantly } \\
\text { higher scores for attitude than did those identifying } \\
\text { as White. }\end{array}$ \\
\hline \multirow[t]{4}{*}{ Intention } & Age & $\begin{array}{l}18 \text { to } 44 \text { year olds had the highest ratings for } \\
\text { intention followed by } 45 \text { and } 64 \text { year olds and } \\
\text { individuals who were } 65+\text { sequentially. }\end{array}$ \\
\hline & Gender & $\begin{array}{l}\text { Males had higher ratings for intention than in- } \\
\text { frequent public transit users. }\end{array}$ \\
\hline & Frequency of Use & $\begin{array}{l}\text { Frequent public transit users had higher intention } \\
\text { than in-frequent public transit users. }\end{array}$ \\
\hline & Ethnicity & $\begin{array}{l}\text { Individuals identifying as Asians and individuals } \\
\text { identifying as Latin American or Hispanics had } \\
\text { higher intention than those identifying as Whites. }\end{array}$ \\
\hline
\end{tabular}

Table 5. Summary of Findings

\section{PROPOSED RESEARCH AGENDA}

In the following sections of this paper, we present recommendations for further research based on the findings above. These recommendations are structured by individual 
differences starting with age and followed by gender, ethnicity, and frequency of bus riding respectively.

\subsection{Age and Acceptance of $A V$ buses}

The results from the survey above indicate that there are significant differences for trust, attitude, and intention across this study's three different age groups. Notably, the older age group $(65+)$ had lower ratings across all three of these metrics when compared to the 18-44 and the 45-64 year old age groups (see findings: 1a, 2a, and 3a). ). It is not clear precisely why older adults have lower ratings for our outcomes but, these results are consistent with existing research (Hauk et al., 2018). Within this literature, perceived ease of use is a common construct used to explain this relationship (Davis, 1989; Gefen \& Straub, 1997; Hauk et al., 2018; Venkatesh \& Morris, 2000). In the context of AV buses, however, is unclear how relevant this construct is as the actual operation of the bus is automated and use is conceptually different as a result.

Aside from the construct of perceived ease of use there is increasing evidence across literatures that type of technology and perceived usefulness of a technology may have a role to play (Melenhorst, Rogers, \& Bouwhuis, 2006; Morris, Goodman, \& Brading, 2007; Selwyn, Gorard, Furlong, \& Madden, 2003). In their meta-analysis, Hauk et al. (2018) determined that perceived usefulness was moderated by type of technology. Specifically, they found that perceived usefulness significantly impacted information technology use when the technologies in question were "growth and knowledge acquisition" rather than "social and emotional need fulfillment" technologies. It is unclear which one of these classifications applies to AV buses but, our results in terms of frequency of bus riding seem to support the argument that individuals who see a technology as more relevant have higher degrees of trust, attitude, and intention to use that technology. Nonetheless, future research is needed to confirm or deny the role of perceived usefulness in relation to AV buses.

\section{Recommendations for Further Research}

Based on the results of this study, new studies should investigate how to promote intention, attitude, and trust in AV buses for older age groups. Studies of this kind may wish to focus on perceived usefulness and determining if, as Hauk et al. (2018) suggests, type of technology (or presentation of) plays a role in explaining the different perceptions of older and younger age groups. In addition, understanding how the concept of use is understood in an AV domain and if perceived ease of use is indeed influential may also help provide insight into the relationship between age group and acceptance of AV buses.

\section{Research Questions - Age Group}

RQ-1.1 What can be done to promote intention to use AV buses for older adults?

RQ-1.2 What can be done to promote attitude toward AV buses for older adults?

RQ-1.3 What can be done to promote trust in AV buses for older adults?

\subsection{Gender and AV Bus Perceptions}

Gender differences have already been found for the acceptance of various technologies and AV buses seem to be no exception. Based on the findings in our study, we saw significant differences between men and women in terms of intention to ride an AV bus (see finding 3b). Why this was the case is not yet fully understood in the con- 
text of AV buses. Related work focusing on AVs, however, does offer some promising insights. Specifically, affect has been found to influence intention to use AVs where men associated positive emotions (pleasure) to AVs and women associated negative emotions (anxiety) to AVs (Hohenberger, Spörrle, \& Welpe, 2016). Prior research has also provided evidence that age moderates gender and intention (Hohenberger et al., 2016; Wang, Wu, \& Wang, 2009). Future research on AV buses may wish to investigate these different constructs and determine if these are applicable to AV buses as well.

Recommendations for Further Research The results of this study demonstrate that there is a difference in intention to ride AV buses between men and women. Specifically, women are less likely than men to ride AV buses. As a result, future researchers may wish to focus on promoting intention to ride AV buses among women. In particular studies of this kind may seek to focus on affect and the possible moderating effect of age.

\section{Research Questions - Gender}

RQ-2 $\quad$ What can be done to promote intention to use AV buses for women?

\subsection{Ethnicity and Acceptance of AV Buses}

In terms of ethnicity, our study revealed several sets of differences (see findings: $2 d$ and 3d). Specifically, we observed that White Americans had the lowest attitudes towards and intention to ride AV buses when compared to Asian Americans and Latinx Americans. The role of ethnicity in acceptance of AV buses and indeed in the broader literature is still unknown as literature directly studying the effects of ethnicity on acceptance and use of technology is scarce.

Recommendations for Further Research Research lines should be established investigating how to promote attitude and intention for White Americans. Additionally, it might be worthwhile for researchers to focus on what different ethnicities have in common and what they have different from each other. This could be of use as it appears that some ethnicities relate to acceptance of AV buses and others do not. One explanation are differences in personal income or other social economics variables. However, it should be noted that such differences could be used to explain the differences between White Americans and Latinx Americans but not necessarily for differences between White and Asian Americans. Yet, this study found both.

Research Questions - Ethnicity

RQ-3.1 What can be done to promote intention to use AV buses for White Americans?

RQ-3.2 What can be done to promote attitudes toward AV buses for White Americans?

\subsection{Conventional Bus Experience and Acceptance of AV buses.}

This study found a series of results demonstrating that frequency of conventional bus use impacts acceptance of AV buses. Consistent across all three of the outcomes in this study we saw that individuals who were in-frequent bus riders had lower trust, attitude, and intention to ride than those that were frequent bus riders (See Findings: $1 b, 2 b$ and $3 c$ ). One possible explanation for this trend is that for in-frequent bus riders there are two factors at play while for frequent bus riders there is only one. For in-frequent riders, these individuals are faced with the prospects of first, using public transportation and second, using an autonomous vehicle. This is in contrast 
with frequent bus riders for whom the AV component is the only factor in play as this population has already formed the intention to use public transportation. This remains to be hypothetical however and future studies may wish to investigate these relationships.

Recommendations for Further Research New research should investigate how one can promote trust, attitude, and intention for in-frequent riders of conventional buses. Studies seeking to investigate this may wish to consider the compounding of technologies and if the fact that AV buses are both AVs and buses is factored into an individual's decision making.

\section{Research Questions - Experience}

RQ-4.1 What can be done to promote intention to use AV buses for in-frequent bus riders?

RQ-4.2 What can be done to promote attitude towards AV buses for in-frequent bus riders?

RQ-4.2 What can be done to promote trust in AV buses for in-frequent bus riders?

\section{CONCLUSION}

AV buses hold great potential to improve access to public transportation. Regardless, acceptance of this technology need to be well understood before any of this potential can be met. In this study, we identified several differences between demographic groups in relation to autonomous buses. Based on the results of this study, this paper offers a series of recommendations for future research. As a result of this study, it is clear that acceptance does indeed differ by individual differences as such they should be taken into account. Further research still needs to be conducted to investigate how these individual differences can be addressed in the design and development of AV buses. At present, there appear to be a large range of barriers to the acceptance of AV buses based on individual differences. It is not yet known how these barriers may be removed but certainly, until they are, acceptance of AV buses will remain limited.

\section{LIMITATIONS}

This study has three limitations. First, although self-report measures are useful and widely utilized in empirical research, subjects often have "limited and imperfect access to many of their own internal mental processes, and may therefore not be able to give accurate responses to questions about these processes" (Lavrakas, 2008, Pg.2). As a result, when presented with a hypothetical scenario individuals may not always act in accordance with their own expectations. Second, the demographic groups and categories utilized in this study were not all encompassing. More specifically, we did not include multiracial ethnic groups or transgender identities in our demographic questionnaire. In utilizing a closed set of demographic traits, we may have inadvertently influenced how individuals choose to categorize themselves. Finally, we did not look at other influential individual factors such as personality that may have influenced individuals as suggested in recent literature (Esterwood \& Robert, 2020; Robert, 2018; Robert et al., 2020). 


\section{Acknowledgement(s)}

This study was funded and supported by the M-City research office under the University of Michigan Office of Research.

\section{References}

Abraham, H., Lee, C., Brady, S., Fitzgerald, C., Mehler, B., Reimer, B., \& Coughlin, J. F. (2017). Autonomous vehicles and alternatives to driving: trust, preferences, and effects of age. In Proceedings of the Transportation Research Board 96th Annual Meeting (TRB'17).

Ajzen, I. (1991). The theory of planned behavior. Organizational behavior and human decision processes, 50(2), 179-211.

Allen, M. (2017). Post hoc tests: Tukey honestly significant difference test (Vol. 4). SAGE Publications.

Azad, M., Hoseinzadeh, N., Brakewood, C., Cherry, C. R., \& Han, L. D. (2019). Fully Autonomous Buses: A Literature Review and Future Research Directions (Vol. 2019). Hindawi Limited.

Bagozzi, R., \& Burnkrant, R. (1985). Attitude organization and the behavior relation: A reply to dillon and kumar. Journal of Personality and Social Psychology, 49, 47-57.

Bansal, P., \& Kockelman, K. M. (2018). Are we ready to embrace connected and self-driving vehicles? A case study of Texans. Transportation, 45(2), 641-675.

Baptista, G., \& Oliveira, T. (2015). Understanding mobile banking: The unified theory of acceptance and use of technology combined with cultural moderators. Computers in Human Behavior, 50, 418-430.

Bazilinskyy, P., Kyriakidis, M., \& de Winter, J. (2015). An international crowdsourcing study into people's statements on fully automated driving. Procedia Manufacturing, 3, $2534-2542$.

Biondi, F., Alvarez, I., \& Jeong, K.-A. (2019). Human-vehicle cooperation in automated driving: A multidisciplinary review and appraisal. International Journal of Human-Computer Interaction, 35(11), 932-946.

Bobbitt, L. M., \& Dabholkar, P. A. (2001). Integrating attitudinal theories to understand and predict use of technology-based self-service: The Internet as an illustration. International Journal of Service Industry Management, 12(5), 423-450.

Charness, N., Yoon, J. S., Souders, D., Stothart, C., \& Yehnert, C. (2018). Predictors of attitudes toward autonomous vehicles: The roles of age, gender, prior knowledge, and personality. Frontiers in psychology, 9, 2589.

Choi, J. K., \& Ji, Y. G. (2015, oct). Investigating the Importance of Trust on Adopting an Autonomous Vehicle. International Journal of Human-Computer Interaction, 31(10), 692-702.

Clark, H. M., American Public Transportation Association, \& CJI Research Corporation. (2017). Who rides public transportation (Tech. Rep.). Washington, DC United States: American Public Transportation Association (APTA).

Creech, C., Jayaraman, S. K., Robert, L., Tilbury, D., Yang, X. J., Pradhan, A., \& Tsui, K. (2017). Trust and Control in Autonomous Vehicle Interactions. Workshop on "Morality and Social Trust in Autonomoy", Robotics Science and Systems Conference(October).

Davis, F. D. (1989, sep). Perceived Usefulness, Perceived Ease of Use, and User Acceptance of Information Technology. MIS Quarterly, 13(3), 319.

Davis, F. D., \& Venkatesh, V. (1996). A critical assessment of potential measurement biases in the technology acceptance model: Three experiments. International Journal of Human Computer Studies, 45(1), 19-45.

Du, N., Haspiel, J., Zhang, Q., Tilbury, D., Pradhan, A. K., Yang, X. J., \& Robert, L. P. (2019). Look who's talking now: Implications of AV's explanations on driver's trust, AV preference, 
anxiety and mental workload. Transportation Research Part C: Emerging Technologies, 104, 428-442.

Du, N., Robert Jr., L. P., Tilbury, D., Pradhan, A. K., \& Yang, X. J. (2018). A Cross-Cultural Study of Trust Building in Autonomous Vehicles. In Conference on Autonomous Vehicles in Society.

Dwivedi, Y. K., Rana, N. P., Jeyaraj, A., Clement, M., \& Williams, M. D. (2019, jun). Reexamining the Unified Theory of Acceptance and Use of Technology (UTAUT): Towards a Revised Theoretical Model. Information Systems Frontiers, 21 (3), 719-734.

Esterwood, C., \& Robert, L. (2020). Personality in healthcare human robot interaction (h-hri): A literature review and brief critique. In Proceedings of the 8th International Conference on Human-Agent Interaction (HAI 2020) (pp. 10-13).

Esteva Armida, E. (2008). Adoption process for voip: The influence of trust in the utaut model. ProQuest Dissertations and Theses, 115.

Faisal, A., Yigitcanlar, T., Kamruzzaman, M., \& Currie, G. (2019). Understanding autonomous vehicles: A systematic literature review on capability, impact, planning and policy. Journal of Transport and Land Use, 12(1), 45-72.

Fishbein, M., \& Ajzen, I. (1975). Belief, attitude, intention, and behavior: An introduction to theory and research. Philosophy Rhetoric, $10(2), 578$.

Fraedrich, E., Cyganski, R., Wolf, I., \& Lenz, B. (2016). User Perspectives on Autonomous Driving: A Use-Case-Driven Study in Germany. Arbeitsberichte, Heft 187, S. 1-111.

Gefen, D., \& Straub, D. W. (1997). Gender differences in the perception and use of e-mail: An extension to the technology acceptance model. MIS Quarterly, 389-400.

Ghazizadeh, M., Peng, Y., Lee, J. D., \& Boyle, L. N. (2012). Augmenting the technology acceptance model with trust: Commercial drivers' attitudes towards monitoring and feedback. In Proceedings of the Human Factors and Ergonomics Society Annual Meeting (Vol. 56, pp. 2286-2290). Sage Publications Sage CA: Los Angeles, CA.

Gkartzonikas, C., \& Gkritza, K. (2019). What have we learned? a review of stated preference and choice studies on autonomous vehicles. Transportation Research Part C: Emerging Technologies, 98, 323-337.

Haboucha, C. J., Ishaq, R., \& Shiftan, Y. (2017). User preferences regarding autonomous vehicles. Transportation Research Part C: Emerging Technologies, 78, 37-49.

Haspiel, J., Du, N., Meyerson, J., Robert, L. P., Tilbury, D., Yang, X. J., \& Pradhan, A. K. (2018, mar). Explanations and Expectations: Trust Building in Automated Vehicles. In ACM/IEEE International Conference on Human-Robot Interaction (pp. 119-120). IEEE Computer Society.

Hauk, N., Hüffmeier, J., \& Krumm, S. (2018, jul). Ready to be a Silver Surfer? A Meta-analysis on the Relationship Between Chronological Age and Technology Acceptance. Computers in Human Behavior, 84, 304-319.

Hegner, S. M., Beldad, A. D., \& Brunswick, G. J. (2019). In automatic we trust: Investigating the impact of trust, control, personality characteristics, and extrinsic and intrinsic motivations on the acceptance of autonomous vehicles. International Journal of Human-Computer Interaction, 35(19), 1769-1780.

Hewitt, C., Politis, I., Amanatidis, T., \& Sarkar, A. (2019). Assessing public perception of self-driving cars: The autonomous vehicle acceptance model. In Proceedings of the 24th International Conference on Intelligent User Interfaces (pp. 518-527).

Higgins, T. (2017, Mar 30). Uber self-driving car crash detailed in police report. (Name - Uber Technologies Inc; Consumer Watchdog; Copyright - Copyright Dow Jones \& Company Inc Mar 30, 2017; Last updated - 2020-08-10)

Hohenberger, C., Spörrle, M., \& Welpe, I. M. (2016). How and why do men and women differ in their willingness to use automated cars? the influence of emotions across different age groups. Transportation Research Part A: Policy and Practice, 94, 374-385.

Holguín-Veras, J., \& Wang, Q. (2011). Behavioral investigation on the factors that determine adoption of an electronic toll collection system: Freight carriers. Transportation Research Part C: Emerging Technologies, 19(4), 593-605. 
Hughes-Cromwick, M. (2019). 2019 public transportation fact book (Tech. Rep.). Washington, DC United States: American Public Transportation Association (APTA).

Hulse, L. M., Xie, H., \& Galea, E. R. (2018). Perceptions of autonomous vehicles: Relationships with road users, risk, gender and age. Safety Science, 102, 1-13.

Iclodean, C., Cordos, N., \& Varga, B. O. (2020). Autonomous shuttle bus for public transportation: A review. Energies, 13(11), 2917.

Jayaraman, S. K., Creech, C., Robert, L. P., Tilbury, D. M., Yang, X. J., Pradhan, A. K., \& Tsui, K. M. (2018). Trust in AV: An Uncertainty Reduction Model of AV-Pedestrian Interactions. In ACM/IEEE International Conference on Human-Robot Interaction (pp. 133-134).

Kaur, K., \& Rampersad, G. (2018). Trust in driverless cars: Investigating key factors influencing the adoption of driverless cars. Journal of Engineering and Technology Management, 48, 87-96.

Kim, D., Chun, H., \& Lee, H. (2014). Determining the factors that influence college students' adoption of smartphones. Journal of the Association for Information Science and Technology, 65(3), 578-588.

Kim, Y. J., Chun, J. U., \& Song, J. (2009). Investigating the role of attitude in technology acceptance from an attitude strength perspective. International Journal of Information Management, 29(1), 67-77.

Kothandapani, V. (1971). Validation of feeling, belief, and intention to act as three components of attitude and their contribution to prediction of contraceptive behavior. Journal of Personality and Social Psychology, 19(3), 321.

Lavrakas, P. J. (2008). Encyclopedia of survey research methods. Sage Publications.

Lee, C., Seppelt, B., Abraham, H., Reimer, B., Fitzgerald, C., Mehler, B., \& Coughlin, J. F. (2018). Consumer comfort with in-vehicle automation: Technology of today drives acceptance of a self-driving future. White Paper 2018-2-MIT AgeLab.

Lee, J. D., \& See, K. A. (2004). Trust in automation: Designing for appropriate reliance. Human Factors, 46(1), 50-80.

Liu, H., Yang, R., Wang, L., \& Liu, P. (2019). Evaluating initial public acceptance of highly and fully autonomous vehicles. International Journal of Human-Computer Interaction, 35(11), 919-931.

Manawadu, U., Ishikawa, M., Kamezaki, M., \& Sugano, S. (2015). Analysis of individual driving experience in autonomous and human-driven vehicles using a driving simulator. In IEEE/ASME International Conference on Advanced Intelligent Mechatronics, AIM (Vol. 2015-Augus, pp. 299-304). IEEE.

Martinez, L., \& Crist, P. (2015). Urban mobility system upgrade-how shared self-driving cars could change city traffic. In International Transport Forum, Paris.

Mathieson, K. (1991). Predicting user intentions: Comparing the technology acceptance model with the theory of planned behavior. Information Systems Research, 2(3), 173-191.

Mcknight, D. H., Carter, M., Thatcher, J. B., \& Clay, P. F. (2011). Trust in a specific technology: An investigation of its components and measures. ACM Transactions on management information systems (TMIS), 2(2), 1-25.

Melenhorst, A.-S., Rogers, W. A., \& Bouwhuis, D. G. (2006). Older adults' motivated choice for technological innovation: Evidence for benefit-driven selectivity. Psychology and aging, $21(1), 190$.

Mitchell, U. A., Chebli, P. G., Ruggiero, L., \& Muramatsu, N. (2019). The Digital Divide in Health-Related Technology Use: The Significance of Race/Ethnicity. Gerontologist, 59 (1), 6-14.

Modeling Consumers' Adoption Intentions of Remote Mobile Payments in the United Kingdom: Extending UTAUT with Innovativeness, Risk, and Trust. (2015, aug). Psychology and Marketing, 32(8), 860-873.

Moris, M. G., \& Venkatesh, V. (2000). Age differneces in technology adoption decisions: Implications for a changing work force. Personnel Psychology, 53(2), 375-403.

Morris, A., Goodman, J., \& Brading, H. (2007). Internet use and non-use: views of older 
users. Universal access in the information society, 6(1), 43-57.

Muir, B. M., \& Moray, N. (1996). Trust in automation. part ii. experimental studies of trust and human intervention in a process control simulation. Ergonomics, 39(3), 429-460.

Neff, J., \& Dickens, M. (2013, jan). Public Transportation Fact Book (Tech. Rep.). Washington, DC United States: American Public Transportation Association (APTA).

Nordhoff, S., de Winter, J., Madigan, R., Merat, N., van Arem, B., \& Happee, R. (2018). User acceptance of automated shuttles in Berlin-Schöneberg: A questionnaire study. Transportation Research Part F: Traffic Psychology and Behaviour, 58, 843-854.

Nordhoff, S., Van Arem, B., Merat, N., Madigan, R., Ruhrort, L., Knie, A., \& Happee, R. (2017). User Acceptance of Driverless Shuttles Running in an Open and Mixed Traffic Environment. In 12th ITS European Congress (pp. 1-14).

Oliveira, T., Faria, M., Thomas, M. A., \& Popovič, A. (2014). Extending the understanding of mobile banking adoption: When UTAUT meets TTF and ITM. International Journal of Information Management, 34(5), 689-703.

Ostrom, T. M. (1969). The relationship between the affective, behavioral, and cognitive components of attitude. Journal of Experimental Social Psychology, 5(1), 12 - 30.

Paddeu, D., Parkhurst, G., \& Shergold, I. (2020). Passenger comfort and trust on first-time use of a shared autonomous shuttle vehicle. Transportation Research Part C: Emerging Technologies, 115, 102604.

Petersen, L., Robert, L., Yang, X. J., \& Tilbury, D. (2019). Situational awareness, driver's trust in automated driving systems and secondary task performance. SAE International Journal of Connected and Autonomous Vehicles, 2(2).

Petersen, L., Tilbury, D., Robert, L., \& Yang, X. (2017). Effects of Augmented Situational Awareness on Driver's Trust in Semi-Autonomous Vehicle Operation. In Proceedings of the 2017 Ground Vehicle Systems Engineering and Technology Symposium.

Petersen, L., Zhao, H., Tilbury, D. M., Yang, X. J., \& Robert, L. P. (2018). The Influence of Risk on Driver's Trust in Autonomous Driving Systems,. In Proceedings of the 2018 Ground Vehicle Systems Engineering and Technology Symposium.

Robert, L. (2018). Personality in the human robot interaction literature: A review and brief critique. In Proceedings of the 24th Americas Conference on Information Systems, Aug (pp. 16-18).

Robert, L., Alahmad, R., Esterwood, C., Kim, S., You, S., \& Zhang, Q. (2020). A review of personality in human-robot interactions. Foundations and Trends(R) in Information Systems, 107-212.

Robert Jr, L. P., \& Sykes, T. A. (2017). Extending the concept of control beliefs: Integrating the role of advice networks. Information Systems Research, 28(1), 84-96.

Rödel, C., Stadler, S., Meschtscherjakov, A., \& Tscheligi, M. (2014). Towards autonomous cars: The effect of autonomy levels on acceptance and user experience. In Proceedings of the 6th international conference on automotive user interfaces and interactive vehicular applications (pp. 1-8).

Schnall, R., \& Bakken, S. (2011, sep). Testing the Technology Acceptance Model: HIV case managers' intention to use a continuity of care record with context-specific links. Informatics for Health and Social Care, 36(3), 161-172.

Selwyn, N., Gorard, S., Furlong, J., \& Madden, L. (2003). Older adults' use of information and communications technology in everyday life. Ageing $\&$ Society, 23(5), 561-582.

Sheppard, B. H., Hartwick, J., \& Warshaw, P. R. (1988, dec). The Theory of Reasoned Action: A Meta-Analysis of Past Research with Recommendations for Modifications and Future Research. Journal of Consumer Research, $15(3), 325$.

Sinner, M., Weidmann, U., \& Nash, A. (2017). What's a bus? defining buses and trains in the age of automation (Tech. Rep.).

Souders, D., \& Charness, N. (2016). Challenges of older drivers' adoption of advanced driver assistance systems and autonomous vehicles. In Lecture Notes in Computer Science (including subseries Lecture Notes in Artificial Intelligence and Lecture Notes in Bioinformatics) (Vol. 9755, pp. 428-440). Springer Verlag. 
Taylor, S., \& Todd, P. A. (1995). Understanding information technology usage: A test of competing models. Information Systems Research, 6(2), 144-176.

Venkatesh, V., \& Morris, M. G. (2000, mar). Why don't men ever stop to ask for directions? Gender, social influence, and their role in technology acceptance and usage behavior. MIS Quarterly: Management Information Systems, 24(1), 115-136.

Venkatesh, V., Morris, M. G., Davis, G. B., \& Davis, F. D. (2003). User acceptance of information technology: Toward a unified view. MIS Quarterly: Management Information Systems, $27(3), 425-478$.

Verberne, F. M., Ham, J., \& Midden, C. J. (2012, oct). Trust in smart systems: Sharing driving goals and giving information to increase trustworthiness and acceptability of smart systems in cars. Human Factors, 54(5), 799-810.

Wang, Y.-S., Wu, M.-C., \& Wang, H.-Y. (2009). Investigating the determinants and age and gender differences in the acceptance of mobile learning. British journal of educational technology, 40(1), 92-118.

Yang, H. D., \& Yoo, Y. (2004). It's all about attitude: Revisiting the technology acceptance model. Decision Support Systems, 38(1), 19-31.

You, S., \& Robert, L. (2019). Trusting robots in teams: Examining the impacts of trusting robots on team performance and satisfaction. In Proceedings of the 52nd Hawaii International Conference on System Sciences.

Yuen, K. F., Chua, G., Wang, X., Ma, F., \& Li, K. X. (2020). Understanding public acceptance of autonomous vehicles using the theory of planned behaviour. International journal of environmental research and public health, 17(12), 4419.

Zhang, Q., Robert Jr.; Lionel P., Du, N., \& Yang, X. J. (2018). Trust in AVs: The Impact of Expectations and Individual Differences. Conference on Autonomous Vehicles in Society: Building a Research Agenda.

Zhang, T., Tao, D., Qu, X., Zhang, X., Lin, R., \& Zhang, W. (2019). The roles of initial trust and perceived risk in public's acceptance of automated vehicles. Transportation Research Part C: Emerging Technologies, 98, 207-220.

\section{About the Authors:}

\section{Connor Esterwood}

Connor Esterwood is a Ph.D student at the University of Michigan's school of information and is a member of the MAVRIC as well as a contributor to the University-Based U.S. Army Center of Excellence for Modeling and Simulation of Ground Vehicle Systems located at the University of Michigan (ARC).

\section{Jessie Yang}

X. Jessie Yang is an Assistant Professor at the Department of Industrial and Operations Engineering, University of Michigan Ann Arbor. She obtained her PhD in Mechanical and Aerospace Engineering (Human Factors) from Nanyang Technological University, Singapore in 2014.

\section{Lionel P. Robert}

Lionel P. Robert Jr. an Associate Professor in the School of Information and core faculty member of the Robotics Institute both at the University of Michigan. He is the director of the Michigan Autonomous Vehicle Research Intergroup Collaboration 
(MAVRIC) and an Association for Information Systems Distinguished Member.

\section{Appendix A. Questionnaire Items Utilized}

\begin{tabular}{ll}
\hline Question & Scale \\
\hline To what extent do you believe the behavior of an autonomous bus can be predicted from moment to moment? & Completely (10) - Not at All (1) \\
To what extent can you count on an autonomous bus to do its job? & Completely (10) - Not at All (1) \\
What degree of faith do you have that an autonomous bus will be able to cope with all systems states in the future ? & Completely (10) - Not at All (1) \\
Overall how much do you trust autonomous buses? & Completely (10) - Not at All (1)
\end{tabular}

Table A1. Questionnaire items used for measuring trust in AV buses

Question $\quad$ Scale

Overall, I find riding an autonomous bus to be a wise move.

Overall, I think autonomous buses are a positive thing.

Overall, I think riding an autonomous bus makes sense.

Overall, utilizing autonomous buses to get from one location to another makes sense.

Strongly Agree (7) - Strongly Disagree (1)

Strongly Agree (7) - Strongly Disagree (1)

作

Table A2. Questionnaire items used for measuring attitude towards AV buses

\begin{tabular}{ll}
\hline Question & Scale \\
\hline If possible I expect to ride an autonomous bus in the future. & Strongly Agree (7) - Strongly Disagree (1) \\
I could see myself riding autonomous buses more frequently in the future if possible. & Strongly Agree (7) - Strongly Disagree (1) \\
I can see myself increasing my autonomous bus use if possible. & Strongly Agree (7) - Strongly Disagree (1) \\
It is likely that I will frequently ride in other autonomous vehicles in the future if possible. & Strongly Agree (7) - Strongly Disagree (1)
\end{tabular}

Table A3. Questionnaire items used for measuring intention to use AV buses 